\title{
Creativity and Entrepreneurship: Complementing each other to Create Success Stories
}

\author{
P.N. Tiwari ${ }^{a^{*}}$, Namita Verma $^{b}$ \\ aDepartment of Commerce, Government Post Graduate College, Rudrapur, Udham Singh Nagar, \\ (Uttarakhand), India \\ ${ }^{b}$ Department of Economics, Uttarakhand Open University, Haldwani, Nainital (Uttarakhand), India \\ Email Id: drpntiwarirudra@gmail.com
}

\begin{abstract}
A creative idea can change the world but to do this it will have to be nurtured by an entrepreneur who can judge the potential of the idea and assess the risks involved. It will have to be groomed. It will have to go through trials. It will have to be implemented by some managers who will guide the team handling the implementation of the idea so that it can see the light of the day. In a nutshell the idea will always require finance, investment, research and management to become a success.

Keywords: Creativity, Entrepreneurship, business, investment, risk.
\end{abstract}

PAPER/ARTICLE INFO

RECEIVED ON: $18 / 02 / 2020$

ACCEPTED ON: 20/04/2020

Reference to this paper should be made as follows:

P.N. Tiwari, Namita Verma (2020), "Creativity and Entrepreneurship: Complementing each other to Create Success Stories", Int. J. of Trade and CommerceIIARTC, Vol. 9, No. 1, pp. $111-120$ 
Creativity and Entrepreneurship: Complementing each other to Create Success Stories

P.N. Tiwari, Namita Verma

\section{INTRODUCTION}

Change is inevitable. Today, when the world is facing the wrath of the novel coronavirus, change is sure to shift gears and speed up to match the speed of revolution. Innovation will be the new 'mantra.' With innovation, creativity will seep in as a necessary ingredient. Creative minds will innovate, but the changes will not see the light without a person who takes the risk of funding the expenditure involved in the research, trial, and marketing of these innovations. Entrepreneurship will thus be an essential part of this creative revolution.

The creative innovator will come up with an idea and look for resources to develop, implement, and commercialize the idea. The entrepreneur will judge the plan, assess the risk, and create a new enterprise and embrace every challenge for the development and implementation of this creative idea. Creativity and entrepreneurship, as they have always done, will go hand in hand. Creativity is one of the things that every leader and entrepreneur needs. Infract, people, rarely laud entrepreneurs for their creativity in problem-solving processes. Creativity is often seen as, therefore, of those in both the writing and design domain.

\section{Why CREATIVE THINKING AND ENTREPRENEURSHIP SHOULD Co-EXIST}

Creativity and Entrepreneurship go hand-in-hand. Creative thinking is an essential tool for any businessperson. Creative thinking isn't concerning arising with concepts. It's concerning having the ability to adapt to new circumstances, navigate uncertainty, and notice solutions as issues arise. All start-ups ought to evolve because of the landscape changes. Perhaps your whole isn't communicating the proper emotions, and you would like to regulate it. Maybe your U.I. isn't performing arts to an adequate degree, and it desires a makeover. Perhaps you even got to come back up with new ways in which to secure funding.

\section{Doing All of those Things Needs Creative Thinking}

i. A start-up's success is predicated on its ability to pivot. Creative thinking is the key to manufacturing new concepts and processes. Typically entrepreneurs get trapped within the success of their initial plan. They feel it's thus beautiful that they ne'er ought to be artistic once more. The entrepreneur's World Health Organization extremely thrive and succeed area unit that World Health Organization will use their creative thinking over and over - those World Health Organization will pivot to scale the corporate or survive a competition. The 1st plan you come back up with is usually simply a transition into another program. In an exceeding start-up, things modification all the time. Adapting to circumstances and moving on to a successive plan is simply a part of the business. But years agone, a start-up was simply a tiny low business. It'd break or 10 years to grow a solid foundation; then, the corporate might scale upwards. Today, start-ups still begin tiny; however, currently, they take associate degree injection of capital that compresses that scaling time-frame. 5 or 10 years turns into one or two. Which compressed time-frame ensures the corporate can change, usually terribly quickly. You've got to create sure that you're artistic enough to rise to the challenge once that happens.

ii. Inventive entrepreneurs bring unique concepts to the table. If most are doing one thing constant method, conventional thinking leads you to continuous practice. You've got to assume creatively and challenge the quality procedures if you wish to succeed. Disruption is bred from that creative thinking. Verify the method Apple modified; however, we expect concerning phones. Before the iPhone, everybody had an analogous internal representation of a phone. You knew what a phone gave the look of and what it did. Then Apple came on and 
adjusted that idea forever. Once you hear "phone," you think that of one thing formed sort of a screen. That's the kind of creative thinking I'm talking concerning. I believe most entrepreneurs are artistic naturally. They're interested in however things area unit did, and what they will do to boost on the method.

iii. Standing out from the group takes an inventive approach. Success as a start-up needs you to point out folks that you're different than your competitors in how. You've got to square outback once I was coming up with for Crashlytics; they were simply a start-up attempting to assist app developers in fathoming once and why their apps crashed. Then they went associate degreed fully modified the method individuals loaded associate degree SDK for an app. within the past; it was a fancy and frustrating method. However, the Crashlytics team created a problem and dropped terrific expertise. Individuals began tweeting concerning what proportion they admired the technique, what percentage higher it was than the established order, and what a relief it was to own this feature. It was revolutionary, and Crashlytics was eventually noninheritable by Twitter. Their artistic answer to a widespread downside was the premise of their success.

iv. creative thinking is concerning pushing your potential and never subsidence. Loads of entrepreneurs find yourself obtaining a bit too snug with their everyday business. They get distracted by the daily routine. And that's dangerous. Only because your business is doing fine, that doesn't mean it can't do higher. Typically sitting back permits a competition to introduce and place you out of business with a lot of artistic answers. Invariably keep brooding about; however, you'll improve your method, your product, your data. Keep your eyes and ears open for brand spanking new concepts, new ways in which to run your business.

v. Once applied to a haul, creative thinking is unbeatable. However, creative thinking isn't merely a flash of inspiration. It's associate degree plus, and typically it'll fail even the foremost artistic designers, artists, or writers. The answer is to continue acting on the matter - to repeat until you've got it right. Typically it should solely take some tries. Different times it'll take days of struggle. However, you can't settle. If you recognize you'll do higher, you've got to continue acting on it. Even though which means redoing an emblem fifteen to twenty times or payment days are electing the proper whole color combination. Start-ups of that area unit versatile concerning their product, that area unit hospitable modification - those area unit those that succeed. That's why having the ability to adapt and work creatively to seek out openings and continue up is essential for any businessperson.

\section{THE ROLE OF CREATIVENESS IN ENTREPRENEURSHIP}

Creativity eliminates the boundaries to the mind-set associated ability set of a capitalist. However, heaps of individuals associate creativeness with a lack of restraint and believe it will cause chaos. Conversely, leadership is all concerning management and order. As such, entrepreneurship and creativeness kind an ideal combination. It no long retakes number-crunching skills and utility to run a palmy business. Overtime, creativeness has become an associate integral element of excellent business acumen. Lack of creativeness might simply drag your business into the stagnation mode.

\section{WHY IS CREATIVENESS IMPORTANT TO ENTREPRENEURS?}

a) High overall success. There is an idea that individuals solely want intelligence to attain everything they have in life. However, it takes time for aspiring entrepreneurs to understand 
that creativeness plays associate integral role further. Unfortunately, heaps of learning establishments stress a lot of on intelligence than power; It might maybe be as a result of intellectual information is measurable wherever as creativeness is challenging to identify. None the less, dynamics ar dynamical, and entrepreneurs are setting out to notice the importance of transfer inventive individuals on board. Creative staff is a game-changer in your company if you harness and form their skills adequately.

b) Increase productivity. Creativity permits associate enterpriser to disconnect from the accustomed associated move into chartless territories to pick out distinctive and helpful solutions. It has, therefore, become essential for each leader and worker to develop creative skills. Entrepreneurs are providing the necessary technological resources like visual collaboration, which is usually confused with video conferencing to assist their staff in discovering innovative solutions and ideas. This is often a very efficient strategy to extend workplace productivity. Innovation associated creativeness brings an enterpriser to the success path.

c) Exploit worker potential. You are in all probability utilizing solely $1 / 2$ your employee's spot entails by not encouraging workplace creativeness. Fortuitously, entrepreneurs progressively notice the ocean of inventive ideas that stay untapped and dormant. The sound of these opportunities may result in improved money methods, exaggerated profit, and fast deciding. Creativeness conjointly permits the associate enterprise to remain earlier than the curve.

d) Transcend boundaries creativity permits entrepreneurs to seek out several path-breaking discoveries. As such, it's essential to allow collisions and blur to require a place to transcend boundaries set by disciplines. That way, it's easier for associate enterprisers to induce new views towards finding money or operational drawback. Creativeness lets associate enterpriser connect distinct aspects and extrapolate possible solutions from unrelated ideas.

e) Encourage important thinking. Creativity is slowly coming up to be one in every of the most effective ways to alleviate issues plaguing today's enterprises. Problem-solving works best once, let alone extraordinarily disciplined and targeted thinking. Entrepreneurs will assume in either different or celebration mode. The cerebration involves sin-depth associate analysis and permits an enterpriser to seek out the first possible answer to social control or money drawback. It allows entrepreneurs to use numerous information sources like accounting packages and pc systems. In distinction, intellection encourages creativeness by sanctioning business homeowners to explore attainable solutions for identical drawbacks. Whereas entrepreneurs will mix each thinking mode, intellection ensures associate enterprise gets the most effective resolution.

f) Foster innovation. Manufacturers produce a unique product not solely to meet client expectations; however, they exceed them further. As such, entrepreneurs got to take care to confirm their product ar relevant and helpful to the users. Whereas it's going to be exhausting to identify this from the start, things begin to induce a lot of evidence as your plan turns into a reality.

This is often the time associate enterpriser begins to understand; however, innovation and invention disagree. The design refers to a replacement, distinctive thought, whereas change is a plan that is as distinctive and helpful because of the origin alone. You would like to be inventive and think about a plan otherwise to be innovative. That way, it's easier to show an idea into a reality. 


\section{INDIA'S ASTONISHING START-UP BOOM}

The Prime Minister Mr. Narendra Modi has declared that this disaster has got to be turned into a chance. This is often a state of affairs ne'er seen before, a challenge being Janus-faced for the first time. Faithful can have different necessities and can offer a chance to the folks that ar enterprising enough to creatively rummage around for ways to cater to those necessities. India has concerning fifty,000 start-ups in India in 2018; around eight,900 - 9,300 of that ar technical chronology LED start-ups 1300 new technical school start-ups were born in 2019 alone implying there are 2-3 tech start-ups born a day. India is that the third-largest specific school start-up location globally India has affected to 3rd on the worldwide list, and currently has a lot of tech-driven start-ups than Israel and China. Solely the U.K. and us stand earlier than it. Then a variety of recent start-ups is rising per annum. By the end of 2020, there are projected to be around a pair of 100 within the country altogether.

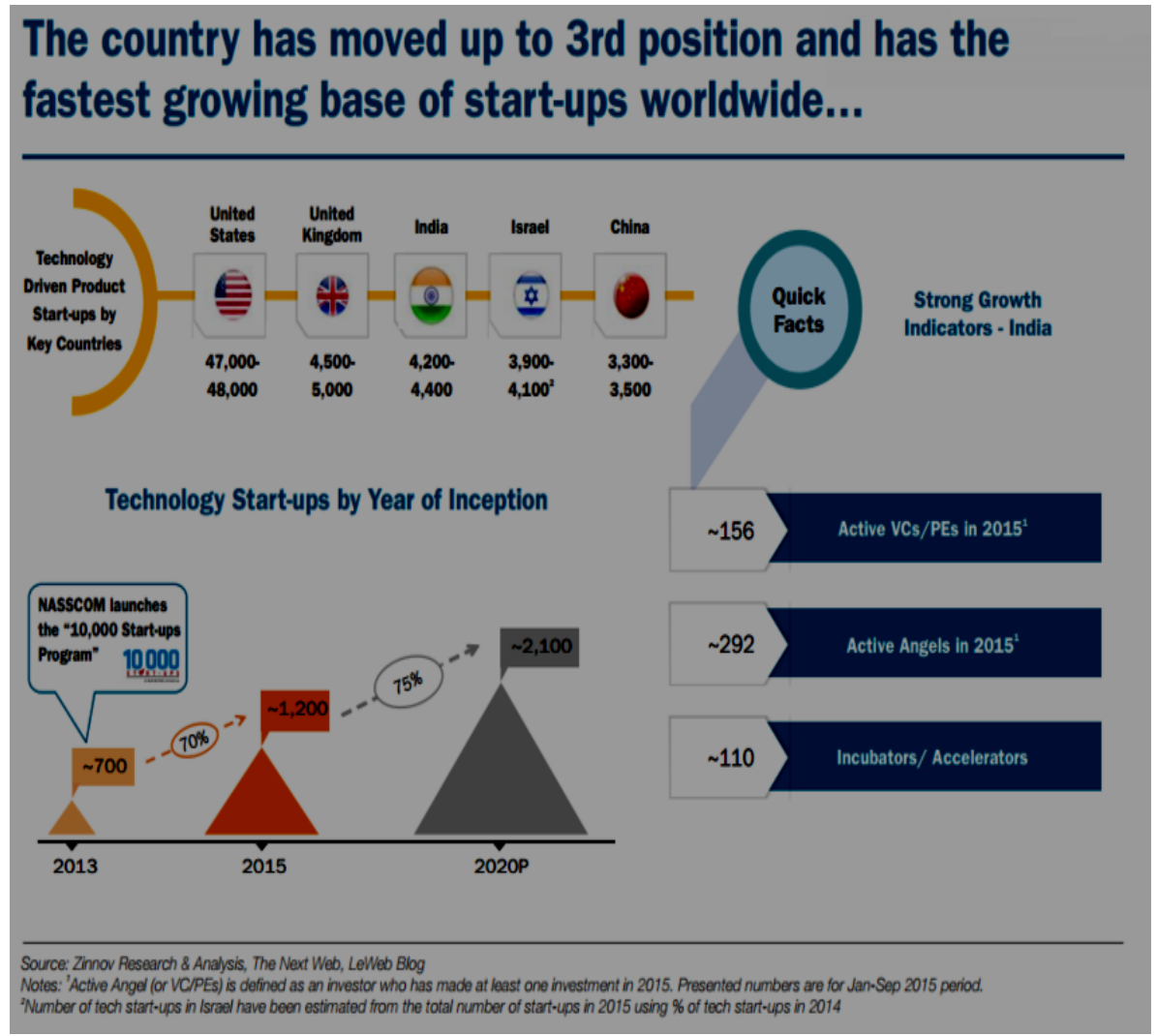

- Funding is concentrated in just three urban areas: In the first half of this year, well over three-quarters of financing was towards just three urban areas-Bengaluru, the National Capital Region (NCR), which includes Delhi; and Mumbai-saw over \$2 billion in the first six months of 2016. 
- Founders are young - the youngest in the world:

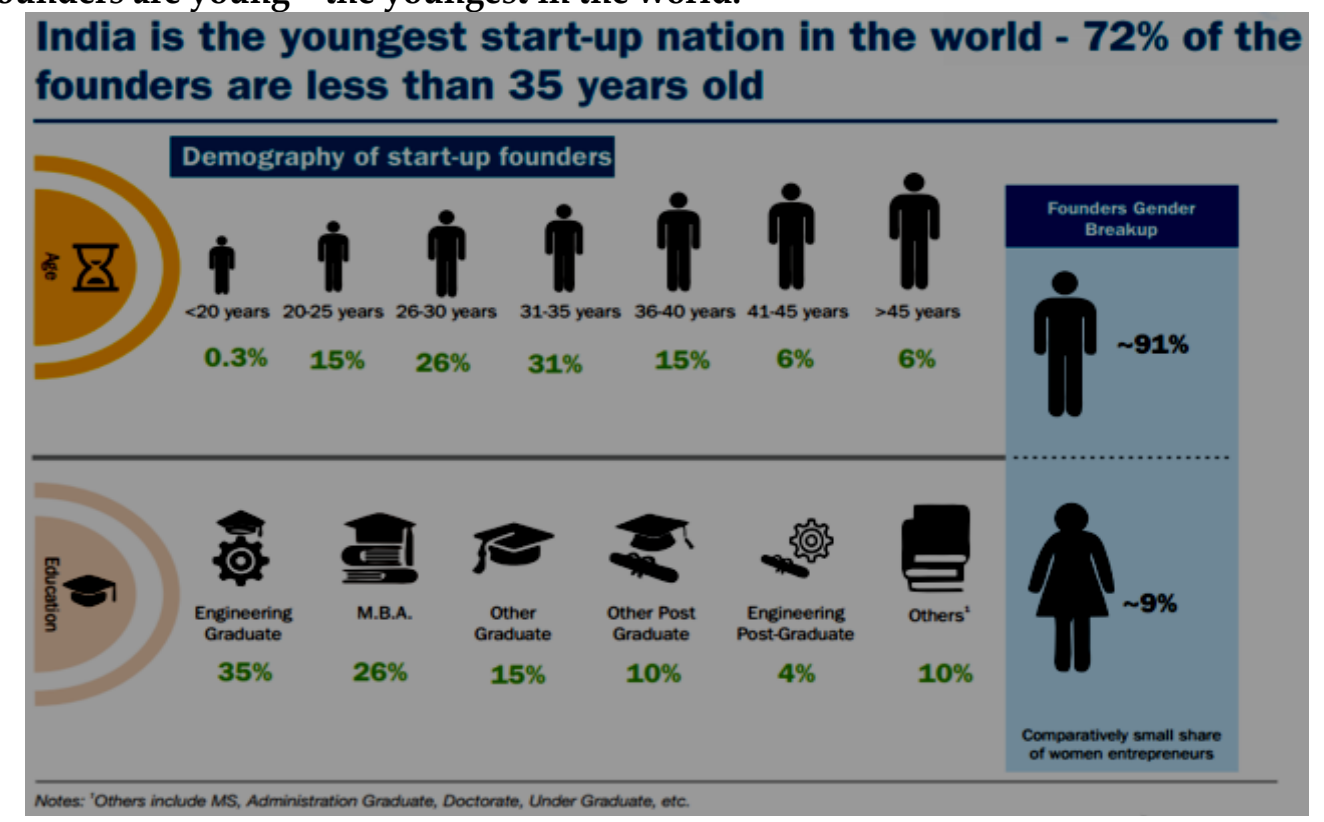

Success Stories: Creative ideas complementing Entrepreneurship

A very classic example of this necessary combination is the motion picture business. It all starts with the idea of a writer. The writer develops the plan with his(his, as per majority, to depict both in further mentions) imagination and research if required. A story is created. It now has to be converted into a screenplay. Often the writer does it on his own but mostly expert steps in to do the job. He prepares the screenplay. A director is now required who can convert the story into a film. The film to be made requires an investment, and here is when an entrepreneur steps in. In this case, the entrepreneur is known as the producer. He, after going through the screenplay, assesses the amount of investment to be made and whether this investment will be able to generate profits. He is considered to be an expert in the assessment of risk. This entrepreneur will produce the film on his own or will need one or more financers. The production depends upon the capability of the producer.

It also depends on the canvas size of the film in question after the assessment of investment and risk comes to the task of engagement. A cinematographer, Light Director, lyricist, singers, choreographer, sound recordist, actors, and scores of other experts are hired. The film is shot in various locations looping in the transport industry. Now comes in the role of an Editor who puts all the footage together and carves out the required scenes. Dubbing and color corrections are made in a studio, and now the film is ready to be released.

Does the producer release the film in theatres? Not always. Most of the time, a premier show is held for the distributors. The distributors watch the movie. It is now their turn to assess the risk in buying the film rights. Once they are done, they buy the rights to showcase the film in theatres located in a specified geographical area. In our case, this area could be the state territories. Other than this, there are overseas rights to showcase the film in foreign countries. The film exhibitors show the movie in their theatres and collect revenue in the form of ticket sales. There are rights to television broadcasts and the internet streaming of the video. 
In this case, there is more than one creative side involved and more than one entrepreneur to implement and showcase the whole idea. The writer, cinematographer, light Director, lyricist, singers, choreographer, sound recordist, and actors are part of the creative side. At the same time, the producer, financier, distributor, exhibitor, television channels, and internet streaming websites form the entrepreneurial team.

Facts show that Epics like Sanskrit literature, sacred writing, and also the Upanishads were primarily narrated. It had been later that they got written and written. And here once more history is repetition itself. It's repetition itself during a vice-versa manner. The written words square measure currently being narrated. It all started with the medical aid of books. Beginning back in 1971, Michael S. Hart launched project pressman and digitized the U.S. Declaration of Independence, turning into the first eBook within the world. Long at that time in 1998, four important events happened: 1) Rocket eBook and Soft book were launched. 2) the primary ISB range was issued to associate degree eBooks. 3) U.S. Libraries, through their websites, currently provided free eBooks to the general public, and 4) Larry Page and Sergey Brin based Google. In 2000, Stephen King offered his novel 'Riding the Bullet' as an alone digital file, and 2 years later, Random House and HarperCollins began to sell digital versions of their publications. In 2004 Sony free its Sony Librie e-reader, so it was Sony Reader in 2006. 2007 modified the globe of reading forever with Amazon's launch of the Kindle eBook reader within the U.S. and also the launch of the iPhone by Apple. In 2009, Barnes \& Noble introduced the Nook, and Sony connected with libraries via the Overdrive digital network to change library patrons to borrow eBooks from their native library.

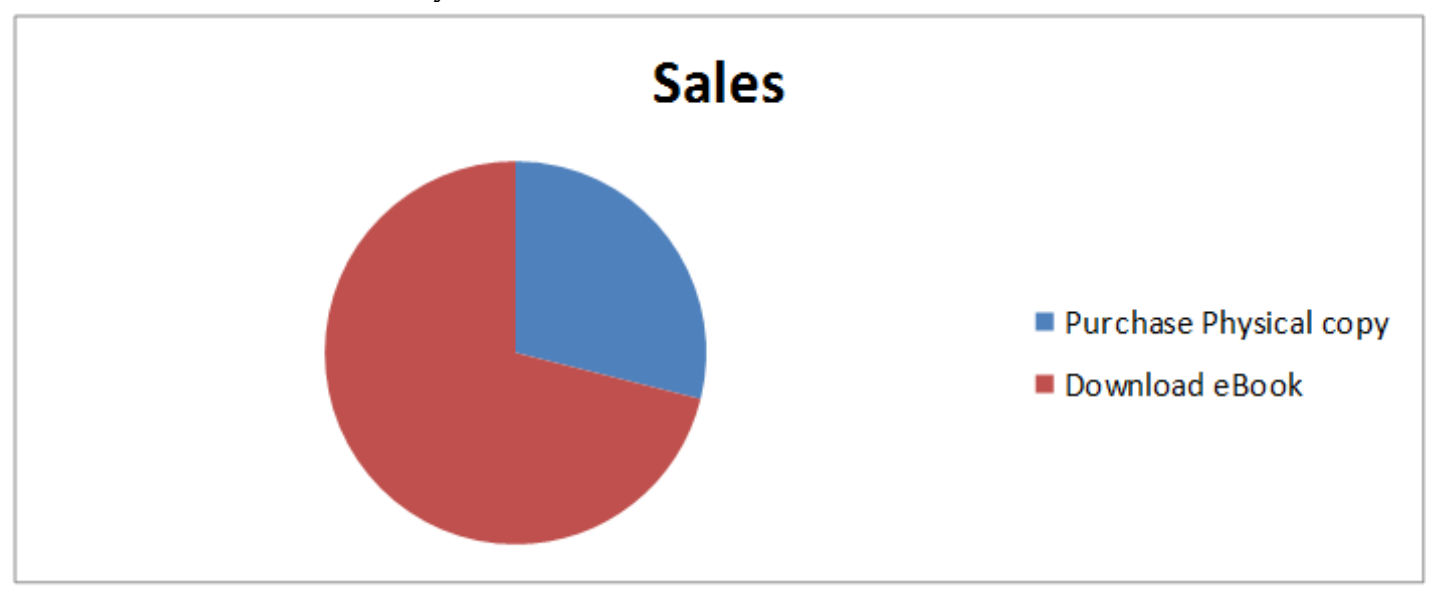

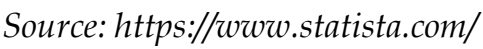

This is just a step towards what I want to point out. eBooks have given way to Audiobooks. Yes, the books which can be heard. Audiobooks are voice recordings of a book that you listen to in place of reading. Audiobooks can be abridged versions, or they can be exact versions of printed books. Smartphone, Tablet, Computer, Home speaker system, or in-car entertainment system. You can listen to audiobooks on any of these mediums.

Audiobooks can be purchased and downloaded like digital music and videos. They can also be bought from online bookstores or downloaded free from public domain sites. Many public library systems now offer audiobook downloads online. 
Today's world is short of time. Every second of our daily-routine, right from waking up to lying down, is scheduled. Where is the time to read? One can ask. Well, this question ought to be asked by people who are not in the business of reading and writing, of course, but on the serious side, the subject provided an opportunity to a creative mind. He thought of converting the books into audio files. Now they don't need space to be stored; they don't require you to sit in one place and devote yourself to reading. These audio files can quickly be hired or bought at an affordable price. They can be listened to while exercising or while doing things that do not require devoted attention. Students can now listen to their lessons on their earplugs while walking to school. The people who are visually challenged can now listen to the books of their choice. That is a bright, creative idea!

To make the idea work, we need an entrepreneur who can convince the writers to allow converting their books into audiobooks. He will find a person who can read aloud and record the album in a voice which keeps the listeners tied up. A sound editor and recordist will be roped in. A recording studio will be required. A company that distributes the audiobook on various online platforms will be needed. A digital marketing company that reaches potential customers and makes them aware is also required.

This is what happens once the inventive mind and entrepreneurial ability be part of hands. Journalist Katz launched the audiobook company edible in 1995 before it was bought over by Bezos for $\$ 300$ million in benefit 2008. within the decade since, loud has dominated the audiobooks market within the North American country. Now, Wal-Mart and Google area unit coming into the sphere. The Audiobook business continues to boom, in line with recent information from the Audio Publishers Association's latest: North American country Publishers rumored Audiobook sales in 2018 that destroyed \$ 940million, a revenue figure that has fullgrown a full twenty four.5\% year-over-year since 2017. Unit sales area unit up even a lot of, rising $27.3 \%$ over 2017. These numbers mark the seventh year in a row that the Audiobook business has seen double-digit growth, marking this latest survey to verify what we tend to understand the rapid already- fireplace success of Audiobooks in recent years. Audio consumption is far up, and publishers all over the area units see revenue growth to match.

Percentages of Audiobook Formats, in Sales/Dollars, (from 2015 to 2019)

\begin{tabular}{|l|c|c|c|c|c|}
\hline \multicolumn{1}{|c|}{ Year } & $\mathbf{2 0 1 5}$ & $\mathbf{2 0 1 6}$ & $\mathbf{2 0 1 7}$ & $\mathbf{2 0 1 8}$ & $\mathbf{2 0 1 9}$ \\
\hline CD & $21.80 \%$ & $16.20 \%$ & $11.30 \%$ & $7.80 \%$ & $4.80 \%$ \\
$\begin{array}{l}\text { Digital } \\
\begin{array}{l}\text { Other (pre-loaded devices, MP3-CD, } \\
\text { apps, book and CD sets) }\end{array}\end{array}$ & $76.80 \%$ & $82.40 \%$ & $87.50 \%$ & $91.40 \%$ & $94.50 \%$ \\
\hline
\end{tabular}

Source: InterQ spring 2020 annual survey. 


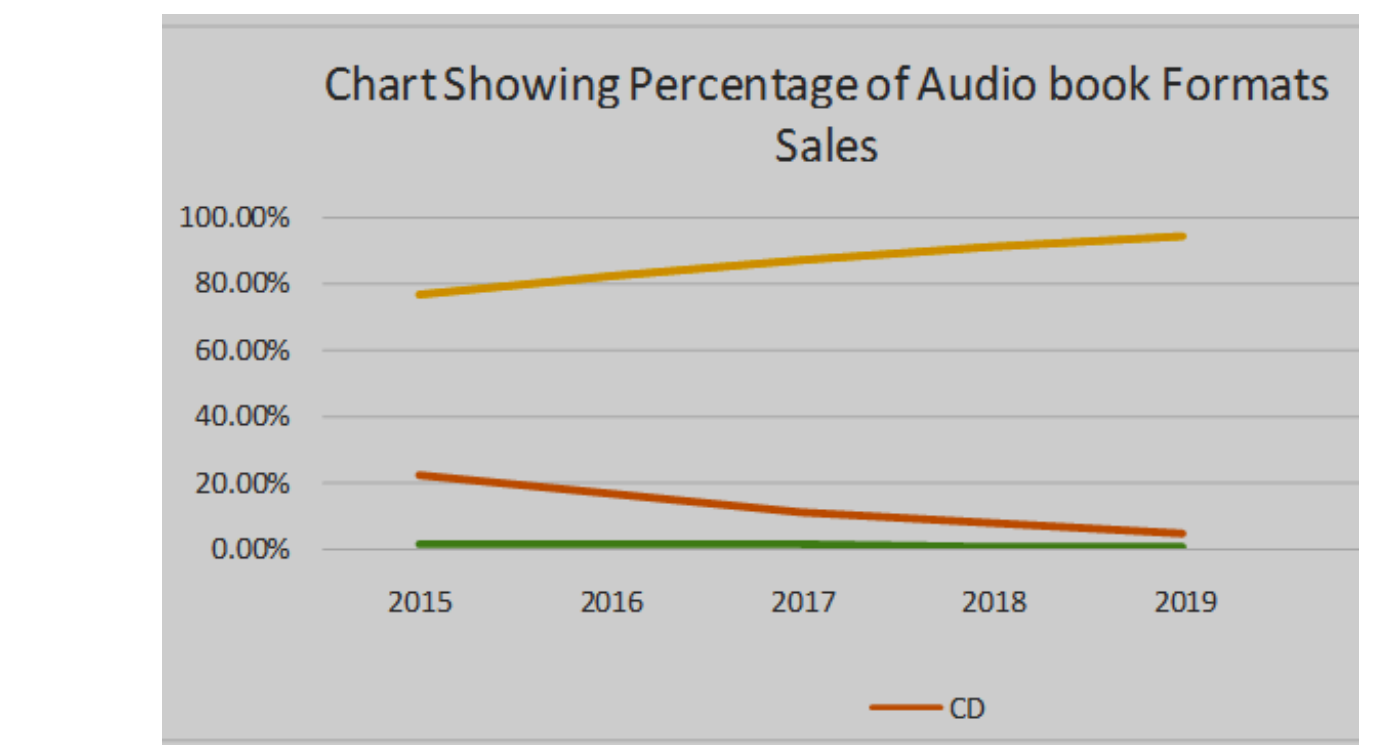

Source: InterQ spring 2020 annual survey.

\section{CONCLUSION}

"The analysis confirms that audio business enterprise continues its upward flight. Seven consecutive years of double-digit growth in really extraordinary." Chris kills CoChair of the APA's analysis Committee and President \& Publisher, Simon \& Schuster Audio, aforesaid in exceeding promulgation. "More Audiobooks area unit being created and additional individuals area unit listening than ever." Audible is reaching intent on Indian producers, creators, and artists to broadcast their work on its platform. Its parent, Amazon, owns a library of books of Indian authors like Mennonite Tripathi, Ashwin Sanghi, Rashmi Bansal, DevduttPatnaik, and Ravi Subramanian through its acquisition of Westland Ltd, an area publisher, in 2016. The fifty-yearold publisher had books within the high ten of the highest fifty charts within the country. The corporate additionally has books in Hindi. Audiobook sales globally totalled \$2.5 billion in 2017, the first recent year that knowledge area unit out there, in step with the Audio Publishers Association. That's concerning nineteen higher from the previous year and virtually thrice the market size once Amazon bought audibly. Storytel is another success story during this field. YogeshDashrath, the Country Manager Republic of India at Storytel, told that Storytel is presently operational in Sweden, Denmark, Finland, Norway, European nation, Poland, Russia, and Espana, additionally to the Republic of India. it's the foremost common streaming service in an exceeding majority of those countries. we've got over [ $\left.{ }^{*} \mathrm{fr} 1\right]$ 1,000,000 paying subscribers. individuals love our service, with ninety-seven news to be glad. In Sweden this year, the entire proportion of audiobooks listened to is obtaining near to sixty-fifths of total physical books oversubscribed. So overall, the response to Storytel has been vastly positive.

Not only these, but many start-ups like Pratilipi, Matrubhumi, etc. have started working in India with the backing of venture capital from prominent venture capital houses.

Examples like these are enough to prove that ideas born in creative minds only when they meet the entrepreneurial minds which develop the concept after proper assessment of potential and risk. A business can thus be said to be an amalgamation of creativity and entrepreneurship. 


\section{REFERENCES}

[1]. Fromm, E.(1959) The Creative Attitude, in Creativity and lt 1 s Cultivation, ed., Harold H. Anderson (New York: Harper and Row, ) 44-54.

[2]. Gaite, A. J. H. (1975) Creativity and classroom organization. Instructor, 84, 38. Dollinger, Marc. J.,(2003), Entrepreneurship, Pearson Education Ltd. New Delhi.

[3]. Hallman, R. J. (1963) The necessary and sufficient conditions of creativity. Journal of Humanistic Psychology, 3:1, Spring.

[4]. Frank Barron (1969), Creative Person and Creative Process, Holt Rine Hart and Winston, New York.

[5]. Rosa, J.A., Qualls, W.J., and Fuentas, C. (2008). "Involving mind, body, and friends: management that engenders creativity," Journal of Business Research, Vol.61, pp.631-639.

[6]. Rothenberg, A. (1979), The Emerging Goddess: The Creative Process in Art, Science, and Other Fields, Chicago, University of Chicago Press

[7]. https://economictimes.indiatimes.com/14Nov2018

[8]. https://govbooktalk.gpo.gov/the-history-of-ebooks.

[9]. https://www.forbes.com/ July 16, 2019

[10]. https://www.statista.com/

[11]. India Today, March 31, 2020.

[12]. InterQ spring 2020 annual survey.

[13]. James W. Frederick Son, "The Comprehensiveness of Strategic Decision Process, Extension, observation, future Directions" Academy of Management Journal 27. No.3, 1984.

[14]. Robbins Stephen.P. and Coutler Mary, Management, Prentice- Hall of India Private Ltd. New Delhi, 1998.

[15]. timesofindia.indiatimes.com, April 8, 2018. 